\title{
A depression of ethanol consumption in rats as a result of intraperitoneal injections of pyrazole
}

\author{
RICHARD ERSPAMER and LOWELL T. CROW \\ Western Washington State College, Bellingham, Wash. 98225
}

When 12 rats were given intraperitoneal injections of pyrazole $(6.6 \mathrm{mmole} / \mathrm{kg})$, a depression of ethanol consumption occurred. Water consumption of experimental and control Ss was not significantly different. It was concluded that the depression effect occurred as a result of the pyrazole.

Pyrazole has been found to inhibit the oxidation of alcohols. Lester \& Benson (1970) confirmed this effect by injecting rats with a $6.6-\mathrm{mmole} / \mathrm{kg}$ dose of pyrazole and measuring the rate of alcohol dissipation from the body. Goldstein \& Pal (1971) used pyrazole to stabilize blood ethanol levels in mice. Reduced dissipation rate would suggest a reduced consumption rate of ethanol, and the present study proposed to investigate this relationship by injecting rats with pyrazole and determining the effects on ethanol consumption.

\section{SUBJECTS}

The Ss were 24 experimentally naive male Holtzman albino rats weighing from 325 to $375 \mathrm{~g}$. The animals were approximately 90 days old at the beginning of the experiment.

\section{APPARATUS}

The Ss were housed individually in $18 \times 25 \times 18 \mathrm{~cm}$ standard metabolism cages (Acme Metal Products). An approximate 24-h light cycle was maintained with room lighting always off between 6:00 a.m. and 6:00 p.m. Volumetric containers were used to determine ethanol and water consumption. Injections of $1 \mathrm{M}$ pyrazole solution were administered intraperitoneally. Ss were given $6 \%$, $12 \%$, and $24 \%(\mathrm{v} / \mathrm{v})$ solutions of ethanol.

Twelve Ss were housed in the apparatus for 36 days. They were allowed to adjust to their new environment during the first 3 days. The possibility of dehydration was minimized with a schedule of alternate alcohol and water days (Crow, 1970). There were four administrations of pyrazole ( $6.6 \mathrm{mmoles} / \mathrm{kg}$ body weight) that occurred in 8-day intervals (on Days $4,12,20$, and 28). The first injection period served as a baseline to determine the effect of pyrazole on water consumption. On alternate days, either ethanol or water was available to the Ss during the last three injection periods. Ethanol only was administered on Days 1, 3, 5, and 7, and water only on Days 2, 4, 6, and 8 . A particular $S$ received the same concentration of ethanol throughout any specific injection period. All Ss experienced all concentrations (6\%, $12 \%$, and $24 \%$ ) of ethanol; a different concentration was presented during each of the last three injection periods. The order of presentation was counterbalanced by presenting the Ss with all permutations of the ethanol concentration sequences. As no sequence effects had been noted previously (Crow, 1971), counterbalancing was considered sufficient control and the data were not analyzed for this influence. Daily measurements of water or ethanol, food consumption, and body weight were made at 9:00 each morning, with pyrazole treatments immediately following on injection days.

Nine days of control data were gathered on a separate group of $12 \mathrm{Ss}$. They were given 3 days to adjust to the new environment. On Days 4, 6 , and 8 they had access to ethanol and food; on Days 5, 7, and 9 they were given free access to food and water. Each animal received 1 day on each concentration of ethanol in counterbalanced order. Daily water or ethanol, food consumption, and weight were recorded. Control data gathered for 3 alcohol days, 1 day for each concentration (as opposed to 4 days on each concentration for the pyrazole group), were considered to be a conservative estimate of consummatory behavior for the present study, as increases in alcohol drinking with prolonged exposure were found previously (Crow, 1970).

\section{RESULTS}

The average consumption of each ethanol concentration over the first 2 ethanol days in each injection period for the pyrazole group was compared to the daily consumption of each ethanol concentration for the control group. At alpha level .025, a Type I analysis of variance (Lindquist, 1953) showed a significant drug effect $(\mathrm{F}=41.1, \mathrm{df}=1 / 22)$ and a significant concentration of ethanol effect
$(\mathrm{F}=40.2, \mathrm{df}=2 / 44)$. The interaction was also significant $(\mathrm{F}=6.57$, $\mathrm{df}=2 / 44$ ).

Figure 1 shows a differential drug effect, pyrazole inhibiting consumption of lower concentrations of ethanol more than the higher concentrations. One-tailed tests showed significant differences (alpha $=.025)$ in the volume of ethanol solution consumed by the $6 \%$ pyrazole $S s$ and both the $12 \%$ $(\mathrm{t}=2.36, \mathrm{df}=11)$ and $24 \%$ pyrazole groups $(\mathrm{t}=4.16, \mathrm{df}=11)$. The difference between the $12 \%$ and $24 \%$ pyrazole groups was not significant. There was a significant difference in ethanol consumption between the $6 \%$ and $12 \%(\mathrm{t}=5.57, \mathrm{~d} f=11), 6 \%$ and $24 \%(t=13.28$, df $=11)$, and $12 \%$ and $24 \%$ control groups $(t=3,40, d f=11)$. A significant difference was also found between the $6 \%$ pyrazole and the $6 \%$ control $(t=5.06, \quad d f=22), \quad 12 \%$ pyrazole and $12 \%$ control $(t=5.11$, df $=22$ ), and the $24 \%$ pyrazole and $24 \%$ control groups $(t=3.69, \mathrm{df}=22)$. ethanol consumption (all concentrations) for the pyrazole and control groups over time. At alpha .025 , another Type I analysis of variance showed significant drug effect $(\mathrm{F}=17.68, \quad \mathrm{df}=1 / 22)$, a significant days effect $(F=8.7, d f=2 / 44)$, and a significant Drug by Days interaction $(\mathrm{F}=30.2, \quad \mathrm{df}=2 / 44)$. One-tailed $t$ tests (alpha .025) showed that Pyrazole Day 1 (PD-1) was not different from PD-2, but PD-3 was significantly different from $P D-1$ and PD-2 $(t=4.70, t=4.40, d f=11)$. No combination of control days (CD) was significantly different. Pyrazole Day 1 was significantly different from CD-1 $(\mathrm{t}=3.28, \quad \mathrm{df}=22), \quad \mathrm{PD}-2$ was significantly different from CD-2 $(t=3.61, \mathrm{df}=22)$, and $\mathrm{PD}-3$ was not significantly different from CD-3.

Food consumption and consequent

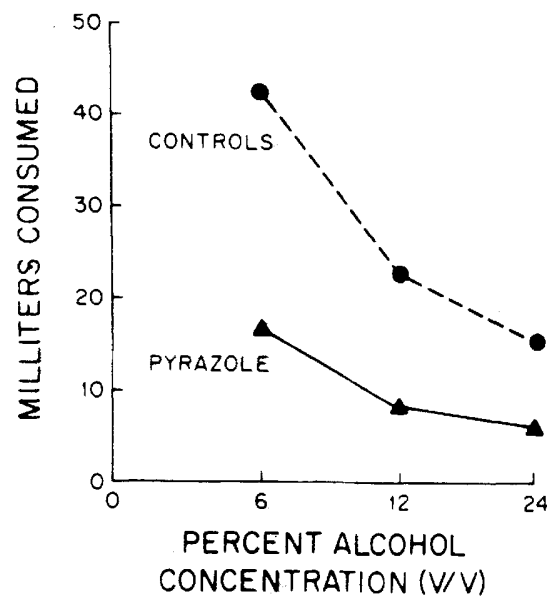

Fig. 1. Ethanol consumption as a function of percent concentration. 


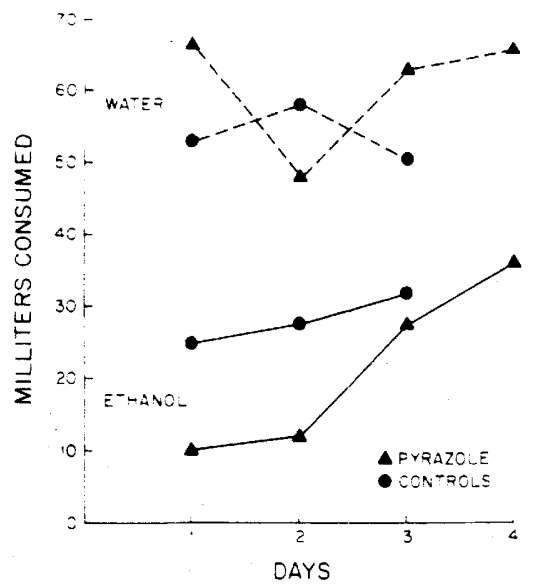

Fig. 2. Ethanol and water consumption as a function of days.

weight change showed a high correspondence with fluid consumption. On alcohol days, food consumption was reduced, but the mean weight of the Ss at the beginning varied less than $5 \%$ with their weight at the finish of the study.

$$
\text { DISCUSSION }
$$

A depression of ethanol consumption was found when rats were injected with a $6.6-\mathrm{mmole} / \mathrm{kg}$ dose of pyrazole. There was a marked difference in ethanol consumption between the control and pyrazole groups, but no significant difference in water consumption. This would imply that pyrazole did not inhibit the ingestion of water. The findings of this study tend to support the 14-h half-life reported for pyrazole (Lester \& Benson, 1970). According to Lester and Benson, only .4\% of the initial dosage would remain in the $S$ at the end of $120 \mathrm{~h}$. The ethanol consumption behavior of the pyrazole group seemed to agree with this estimation. By the third ethanol day, the alcohol consumption of the pyrazole group had reached about the same level as the control group
(Fig. 2). Pyrazole depression of ethanol consumption in rats does not appear to be due to simple debilitation, and it is perhaps involved with the slowing of alcohol metabolism.

\section{REFERENCES}

CROW, L. T. Water metabolism with prolonged ethanol consumption in the rat. Psychological Reports, 1970, 27, 675-677.

CROW, L. T. Alcohol ingestion in rats following median eminence lesions. Psychonomic Science, 1971, 22, 36-37. GOLDSTEIN, D. B., \& PAL, N. Alcohol dependence produced in mice by inhalation of ethanol: Grading the withdrawal reaction. Science, 1971,172 , withdrawa

LESTER, D., \& BENSON, G. D. Alcohol oxidation in rats inhibited by pyrazole. oximes, and amides. Science, 1970, 169, 282-283.

LINDQUIST, E. F. Design and analysis of experiments in psychology and education. Boston: Houghton-Mifflin, 1953. Pp. 266-273. 